\title{
The Regional Geo-economic Dynamics of Turkey in the Context of Europe: 2000-2014 the Emergence of Turkey as One of the Leading Geo-economic Powers of Europe
}

\author{
John Karkazis \\ Department of Shipping, Trade and Transport, University of the Aegean, Chios, Greece \\ Email address: \\ ikarkazis@aegean.gr \\ To cite this article: \\ John Karkazis. The Regional Geo-economic Dynamics of Turkey in the Context of Europe: 2000-2014 The Emergence of Turkey as One of \\ the Leading Geo-economic Powers of Europe. Journal of World Economic Research. Vol. 8, No. 2, 2019, pp. 25-39. \\ doi: 10.11648/j.jwer.20190802.11
}

Received: April 17, 2019; Accepted: June 3, 2019; Published: December 27, 2019

\begin{abstract}
This paper focuses on the location of areas that can competently serve as global or regional supply centers in Europe and particularly in Turkey. In this context it analyses the subsequent polarization process introduced by the supply centers gravitational forces and the impact of key strategic features of European transport networks on the geo-economic dynamics of Europe and Turkey during the period 2000-2014. The main conclusion of this paper regards the establishment of France and Germany in western Europe and Turkey in the eastern Europe as the main geo-economic powers of it. In particular, southwestern Germany and eastern France accommodated all social and economic single gravity centers of Europe for all types of scale economies. Furthermore one basic characteristic of the single location gravity system is its remarkable intra-time locational stability. Regarding the dual gravity systems of Europe, during the period 200-2014 northeastern France retained a geo-economic dominance over the western group of gravity centers whereas Turkey was the dominant geo-economic power in the eastern group of gravity centers. During the same period the social subsystem of the triple gravity systems of Europe exhibited remarkable stability whereas the economic subsystem of them remarkable instability. Throughout this period Turkey was the dominant geo-economic power in the eastern Europe accommodating all gravity centers of the eastern pole of the triple gravity systems of it.
\end{abstract}

Keywords: Turkey, Geo-economic Dynamics, Supply Centers

\section{The Notion of Regional Efficiency}

Key concept

The notion of the geo-economic gravity system will be introduced in this paper as a conceptual tool in the analysis of the key issue of regional efficiency and as a modeling tool in the effort to tackle the above problems.

Basic aim

One of the basic aims of relevant research is to act as a supportive tool in the process of introduction and promotion of policies enhancing the ability of administrative units (provinces, regions or states) to better exploit the capabilities of their infrastructure as well as of their human and natural resources so as to attain sustainable growth both in the social and the economic sphere.

The notion of efficient regions
The notion of regional efficiency, that will be employed in this paper as a basic conceptual and modeling tool, characterizes administrative units or areas possessing hidden, partially or fully exploited comparative geo-economic advantages. Note that the modeling of the above problem is a very difficult process and relevant attempts were not always fully convincing.

\section{Modeling Regional Efficiency}

\subsection{Modeling Approaches}

The modelling approaches of regional efficiency can be distinguished into two basic categories: 
1. the systemic approach and

2. the cost approach

\subsection{The Systemic Approach}

\subsubsection{Model Categorization}

The systemic approach encompasses models that can be further distinguished into two categories:

1. frontier analysis models and

2. regional image attractiveness models

\subsubsection{Frontier Analysis Models}

Frontier analysis models express regional efficiency through an input-output systemic structure:

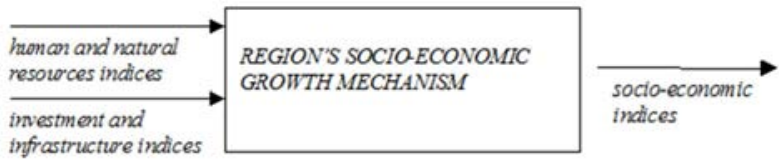

Figure 1. Frontier analysis models.

In general, a region is considered efficient if it can best exploit existing inputs (resources, investments and infrastructure) so as to produce high levels of socio-economic growth.

\subsubsection{Selected Applications}

Karkazis and Thanassoulis [5] applied this approach to assess the effectiveness of regional development policies in Northern Greece using Data Envelopment Analysis (DEA), a specialized linear programming based method.

In the above context, Athanassopoulos and Karkazis [4] introduced the concept of Systemic Duality as a modeling tool to analyze regional growth sustainability and they applied it to assess the effectiveness of the prefectures of Greece.

\subsection{The Cost Approach}

\subsubsection{The Concept of Supply Centers}

In the cost approach the key concept of regional efficiency is expressed as the geo-economic ability of an area to act as a distribution (supply) center under cost criteria. The notion of the supply center is expressed by a system of facilities, with the necessary infrastructure, supplying surrounding areas with services or products at low cost. The notion of cost covers both the cost of establishing and operating the facilities as well as the associated transport cost. The demand of the surrounding areas on services or products, in general, is usually expressed by regional summary measures such as population, GDP, Manufacturing Value Added (MVA), imports etc.

\subsubsection{Determining Factors}

The geo-economic ability of an area to act as a distribution center lies mainly on two factors:

1. Its spatial position on transport networks connecting wider geographical areas (position centrality) and

2. Its infrastructure and on its human and exploitable natural resources that offer economies-of-scale (profile attractiveness)

\subsection{The Concept of Geo-economic Gravity Centers}

Areas, capable of attracting supply center facilities, will be thereon termed Geo-economic Gravity Areas and the supply centers attracted by them Geo-economic Gravity Centers. Geo-economic Gravity Centers will be characterized as Social or Economic if demand summary measure is the population or GDP respectively.

Selected applications

Karkazis [10] introduced the simple Geo-Economic Gravity Model and applied it to E.U. regions. According to his findings the Social Gravity Center of E.U. during the period 1985-1994 was located in northeastern France moving at a rather low for the size of E.U. velocity of $5 \mathrm{~km}$ per annum towards Belgium. During the above period the Economic Gravity Center of E.U. exhibited a significant relocation moving at a velocity of $20 \mathrm{~km}$ per annum from the northwestern part to the southeastern part of Belgium. In 1985 it was located between the city of Brussels and the city of Lille in France whereas in 1994 it was located near the city of Namur in Belgium.

Karkazis [6] applied the simple Geo-Economic Gravity Model to the Balkan countries. According to his findings all three Geo-Economic Gravity Centers analyzed (Social, Economic and Industrial) were located in Turkey.

\section{The Geo-economic Gravity Model}

\subsection{The n-Facilities Location Problem}

The n-Facilities Location Problem regards the location of $n$ non-competing supply facilities in a geographical area which will fully cover the demand for services (public sector or social type facilities) or commodities (private sector or economic type facilities) of a system of area-type demand poles at a minimum, fixed and transport, cost.

\subsection{The Concept of Area-Type Demand Poles}

Area-type demand poles represent large spatial conglomeration of demand points such as an urban area or even an administrative unit (province, region or a state). In the context of the modeling process, area-type demand poles are spatially represented by a central point inside them, usually the location of the corresponding administrative center. Note also that, in the context of regional development approaches, the demand of large geographical areas (cities or administrative units) can be represented by summary measures such as their population, their GDP, their Manufacturing Value Added or their imports.

\subsection{Versions of the Problem}

The n-Facilities Location Model has two methodological versions:

1. The n-Facilities Location Model on a transport network 
(the network case)

2. The n-Facilities Location Model on the plane (the planar case)

Note that the type of distance involved in the second version is the euclidean distance.

\subsection{Selected Applictions}

Weber [1] introduced the 1-Facility Location Problem on the plane with a linear cost function whereas Weiszfeld [2] introduced a rapidly converging algorithm for its solution.

Boffey and Karkazis [3] introduced efficient optimal algorithms for the n-Facilities Location Problem on a transport network.

\subsection{The Geo-economic Gravity Model}

In the case of area-type demand poles coinciding with administrative units (provinces, regions, states etc.) corresponding n-Facilities Location Model will be called thereon Geo-Economic Gravity Model since the role of the network nodes attracting supply facilities is played by administrative units which exercise geo-economic type gravitating forces on their environment. The solution of this model, that is the system of the $\mathrm{n}$ supply center locations minimizing corresponding transport cost function, will be called thereon Geo-Economic Gravity System.

\subsection{The Concept of Social, Economic, Industrial and Trade Gravity Systems}

If the demand summary measure is regional population then the corresponding Geo-Economic Gravity System will be called Social Gravity System. This system of supply centers is associated with public sector facilities offering social services. On the other hand, if the demand summary measure is regional GDP, regional Manufacturing Value Added or regional imports then the corresponding GeoEconomic Gravity System will be called Economic, Industrial or Trade Gravity System respectively.

In order to distinguish between the various values $n$ is taking in the applications performed in this paper, the GeoEconomic Gravity Systems corresponding to the values $n=1$, 2 and 3 will be thereon called simple, dual and triple GeoEconomic Gravity Systems respectively.

\section{The Simple Geo-economic Gravity Model}

The simple Geo-economic Gravity Model regards the location of an administrative region $\mathrm{R}^{*}$ (actually its capital $\mathrm{C}^{*}$ ) within a state, or a wider conglomeration of administrative units, to accommodate a (national etc.) supply center which will cover corresponding demand at a minimum cost. Location (capital) $\mathrm{C}^{*}$ will be called thereon geoeconomic gravity center.

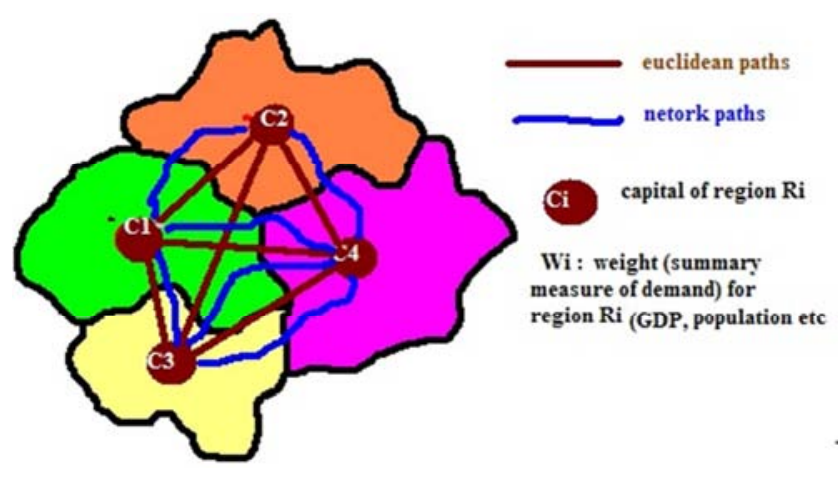

Figure 2. The simple Geo-economic Gravity Model.

$$
\operatorname{Cost}\left(C^{*}\right)=\operatorname{Min}_{i} \operatorname{Cost}\left(C_{i}\right)=\operatorname{Oper}\left(C_{i}\right)+\operatorname{Tot} T\left(C_{i}\right)
$$

where $\operatorname{Cost}(\mathrm{C})$ is the total cost for operating a supply center at location $\mathrm{C}\left(\mathrm{C}=\mathrm{C}_{1}, \mathrm{C}_{2}, . ., \mathrm{C}_{\mathrm{n}}\right)$, Oper(C) the operational and $\operatorname{Tot}(\mathrm{C})$ the transport cost associated with $\mathrm{C}$. Note that $\mathrm{Ci}$ is the capital of region $\mathrm{Ri}$ (figure 2). The transport cost of establishing a supply center at capital $\mathrm{Ci}$ is given by the following formula:

$$
\operatorname{Tot} T(C i)=\sum j=1,2, . . n T(W j, D i j)
$$

where $\mathrm{Wj}$ is the summary measure of demand for region $\mathrm{Rj}$, Dij is the $\mathrm{km}$ distance between network nodes (capitals) $\mathrm{C}_{\mathrm{i}}$ and $C_{j}$ and $T(W, D)$ is the cost for transporting $W$ units of demand at a distance $\mathrm{D}$.

Function T(W,D)

Function $\mathrm{T}(\mathrm{W}, \mathrm{D})$ is taken to be a quadratic polynomial with respect both to $\mathrm{W}$ and $\mathrm{D}$, the simplest polynomial capable of expressing scale economies and dis-economies. Function $\mathrm{T}$ is equipped with two modulator parameters $\mathrm{Kw}$ and $K_{D}$ which determine if $T$ is linear with respect to $W / D$ respectively, or if it is characterized by scale-econnomies with respect to $\mathrm{W}(\mathrm{dT} / \mathrm{dW}<0)$ or $\mathrm{D}(\mathrm{dT} / \mathrm{dD}<0)$, or finally if it is characterized by scale-dis-econnomies with respect to $\mathrm{W}$ $(\mathrm{dT} / \mathrm{dW}>0)$ or $\mathrm{D}(\mathrm{dT} / \mathrm{dD}>0)$. With respect to the applications of section 5 modulator parameter $\mathrm{Kw}$ takes the following values:

1. $\mathrm{Kw} / \mathrm{K}_{\mathrm{D}}=1: \mathrm{T}(\mathrm{W}, \mathrm{D})$ is linear with respect to $\mathrm{W} / \mathrm{D}$,

2. $\mathrm{Kw} / \mathrm{K}_{\mathrm{D}}=0.5$ : $\mathrm{T}(\mathrm{W}, \mathrm{D})$ exhibits strong economies of scale with respect to $\mathrm{W} / \mathrm{D}$.

For this case, if $\mathrm{W}^{*}=\mathrm{MAXi}$ Wi then the unit per quantity transport cost $\left(\mathrm{T}\left(\mathrm{W}^{*}, \mathrm{D}\right) / \mathrm{W}^{*}\right)$ is $50 \%$ lower than the corresponding cost for the linear case and if $\mathrm{D}^{*}=\mathrm{MAXi}$, Dij then the unit per distance transport cost $\left(\mathrm{T}\left(\mathrm{W}, \mathrm{D}^{*}\right) / \mathrm{D}^{*}\right)$ is $50 \%$ lower than the corresponding cost for the linear case.

3. $\mathrm{Kw} / \mathrm{K}_{\mathrm{D}}=1.5$ : $\mathrm{T}(\mathrm{W}, \mathrm{D})$ exhibits strong dis-economies of scale with respect to $\mathrm{W} / \mathrm{D}$.

For this case, if $\mathrm{W}^{*}=\mathrm{MAXi}$ Wi then the unit per quantity transport cost $\left(\mathrm{T}\left(\mathrm{W}^{*}, \mathrm{D}\right) / \mathrm{W}^{*}\right)$ is $50 \%$ higher than the corresponding cost for the linear case and if $\mathrm{D}^{*}=\mathrm{MAXi}, \mathrm{j}$ Dij then the unit per distance transport cost $\left(\mathrm{T}\left(\mathrm{W}, \mathrm{D}^{*}\right) / \mathrm{D}^{*}\right)$ is $50 \%$ higher than the corresponding cost for the linear case.

Regional Discrimination Cost

In order to express in simple and easily compared terms the total cost (operational and transport) associated with a 
supply center established at node (regional capital) $C_{i}$ we introduce the notion of normalized transport cost or Regional Discrimination Cost (RDC) for the capital of region $R_{i}$ :

$$
\operatorname{RDC}(\mathrm{Ci})=\operatorname{Cost}(\mathrm{Ci}) / \operatorname{Cost}\left(\mathrm{C}^{*}\right)>=1 \text { for all } \mathrm{i} .
$$

Note that if $\mathrm{RDC}(\mathrm{Ci})$ is equal to $r$ then $\operatorname{Cost}(\mathrm{Ci})$ is $(\mathrm{r}-1) \%$ higher than corresponding cost at gravity center $\mathrm{C}^{*}$.

\section{European Geo-economic Dynamics and Applications of the Geo-economic Gravity Model in Europe}

Karkazis [8] analyzed the impact of transport costs on the European geo-economic dynamics and the role and significance of Turkey in them. On the other hand Turan [11] analyzed the geo-economic position of Turkey within the Mediterranean and the balancing role of geopolitics. Karkazis and Baltos [19] analyzed the role of a Geo-Economic Gravity System as a methodological tool in regard with the key issue of regional efficiency, as well as a modeling tool in the effort to face relevant socio-economic problems. The authors applied their analysis in the case of Turkey.

Baltos et al [18] provided a functional assessment of a country's dynamics at a regional power level, through the development of a tool which shall examine the working hypothesis of a given country's candidacy to emerge as a regional power and applied it in the case of Turkey.

The principal dimension, in the context of the analysis of geo-economic dynamics and gravity systems, is the strategic analysis of relevant transport systems. In the above context Karkazis and Baltos [20] paid special attention to the roads network development at a regional basis as an effective methodological tool for determining the notion of regional efficiency and applied it in the case of Turkey.

In the above context the report of the Turkish Ministry of
Transport titled "Transport Operational Program 2007" [7] constitutes a major strategic analysis tool for the establishment and development of transportation and communication systems and services in line with national needs. On the other hand, the significance of Istanbul as a major hub in Turkish and pan-European road networks is analyzed by Dholakia et al [9]. Another major document for the analysis of the strategic role of infrastructure investments in Turkish road network is the report of the Turkish Ministry of Transport titled "Investing in Transport Infrastructure of Turkey 2014" [17].

The development of special purpose Geographic Information Systems (GIS) is of outmost importance for regional and especially for strategic transport analysis. EUROSTAT has developed a major GIS for the regions of Europe, the Geographic Information System for the Commission (GISCO) [21]. The GISCO database contains core geographical data for all of Europe such as administrative boundaries, but also thematic geospatial information, for instance population grid data. The geoeconomic analysis presented in this paper was assisted by three specialized GIS performing advanced regional and transport analysis for Europe and Turkey [14-16].

For the evaluation of single, dual and triple geo-economic gravity centers and corresponding transport costs the GIS Ptolemeos - Regional Europe [15] was applied (Figures 1320). The nodes of corresponding road network coincide with the 252 regional capitals of inland NUTS 2 regions of E.U. countries, Turkey and Northern Macedonia. For the evaluation of shortest path distances an appropriately modified version of the branch-bound method was employed. The period of analysis was 2000-2014 and the source of data was EUROSTAT. The inbuilt automated author report writer of the above GIS was also employed to develop a series of geo-economic reports for Germany [12] and Turkey [13].

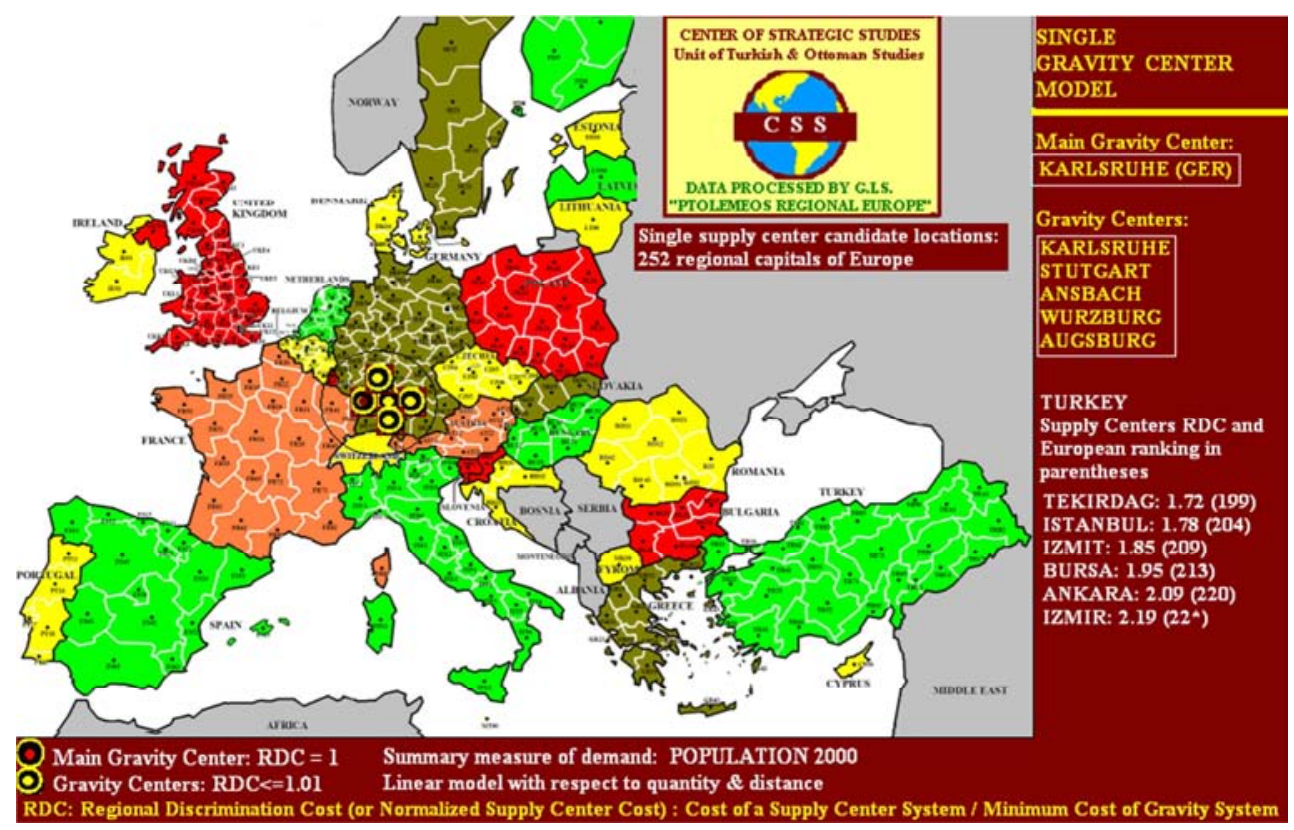

Figure 3. Single Gravity Centers of Europe. Population 2000. Linear case. 


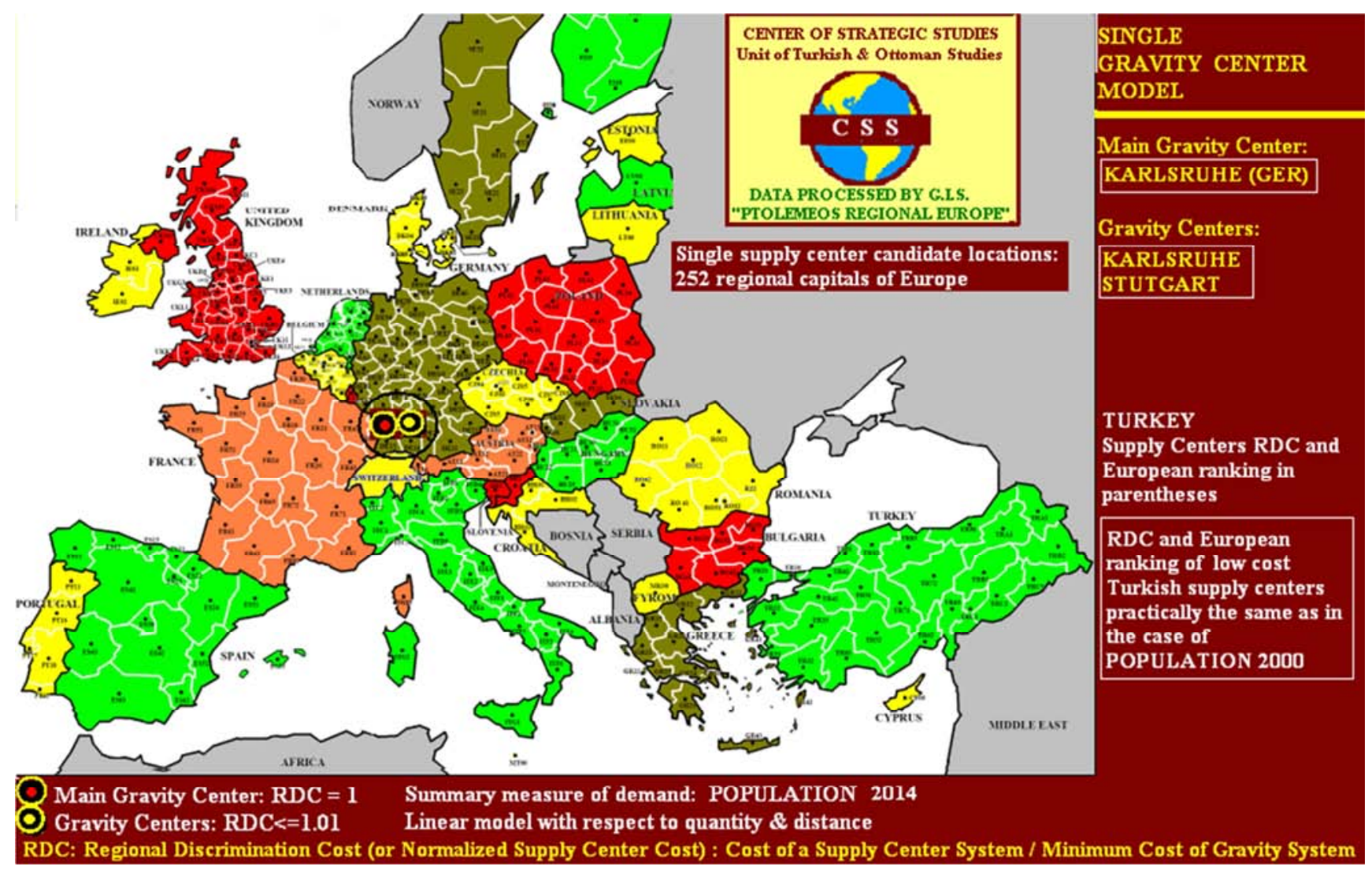

Figure 4. Single Gravity Centers of Europe. Population 2014. Linear case.

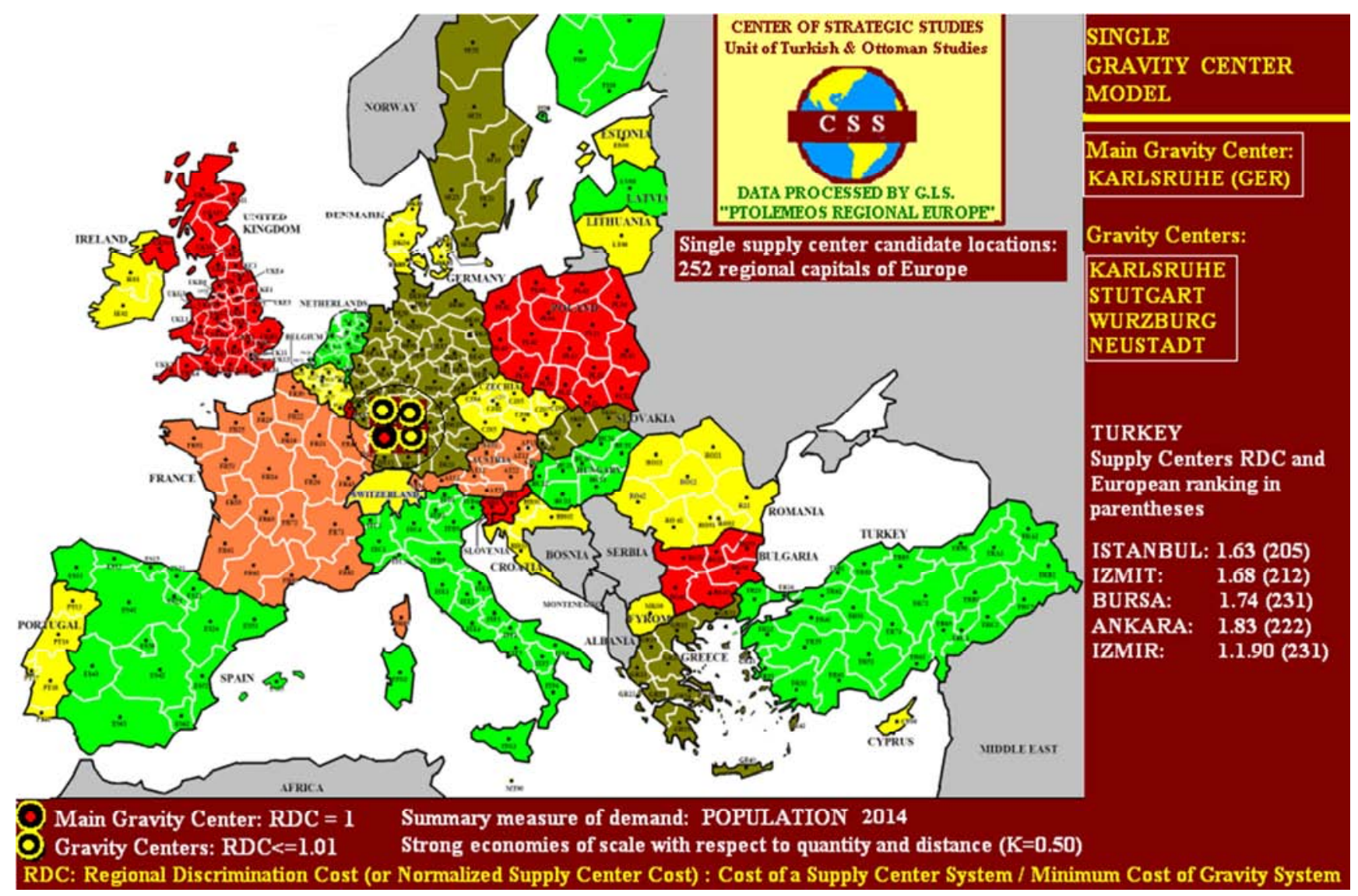

Figure 5. Single Gravity Centers of Europe. Population 2014. Strong scale economies. 


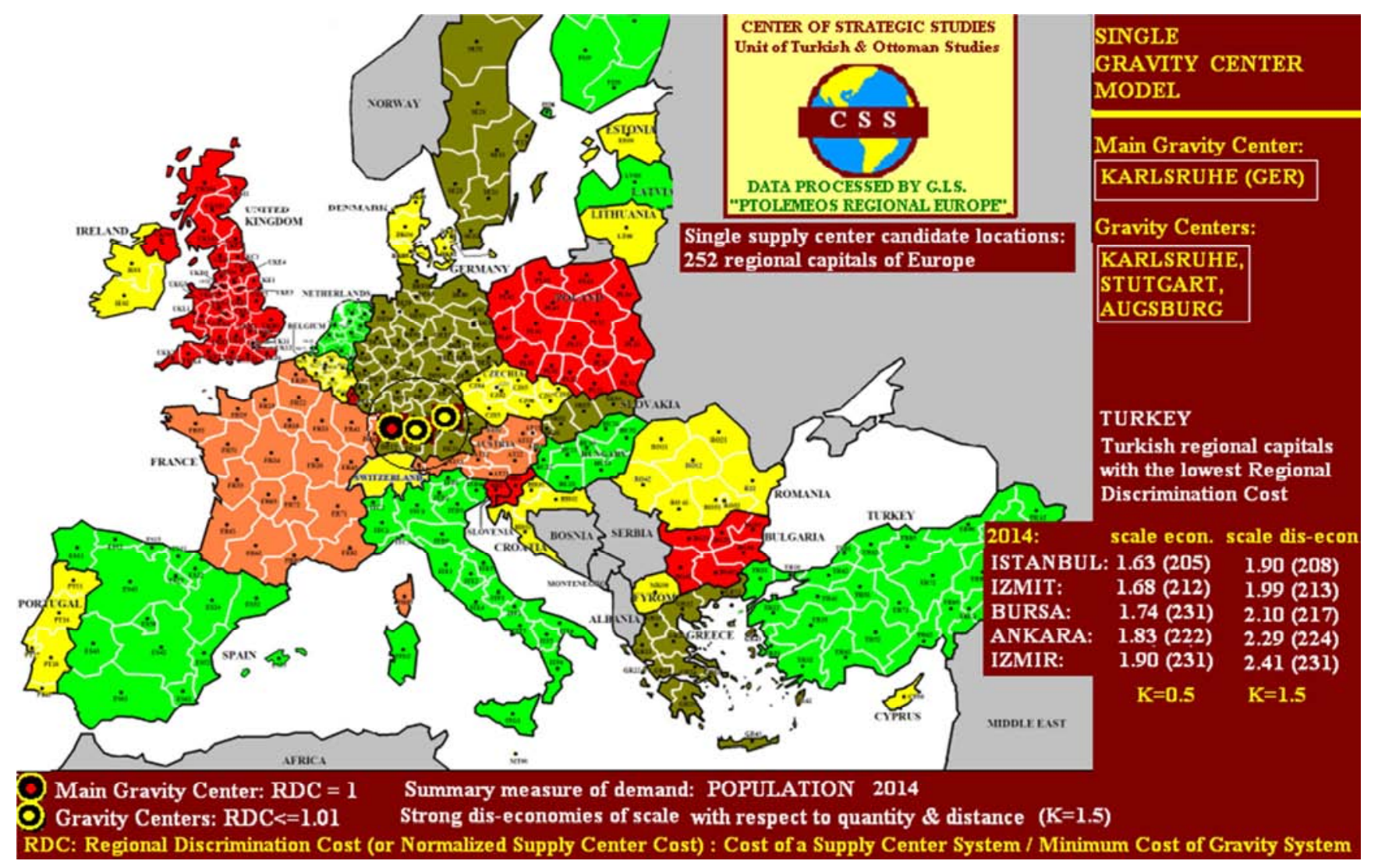

Figure 6. Single Gravity Centers of Europe. Population 2014. Strong scale dis-economies.

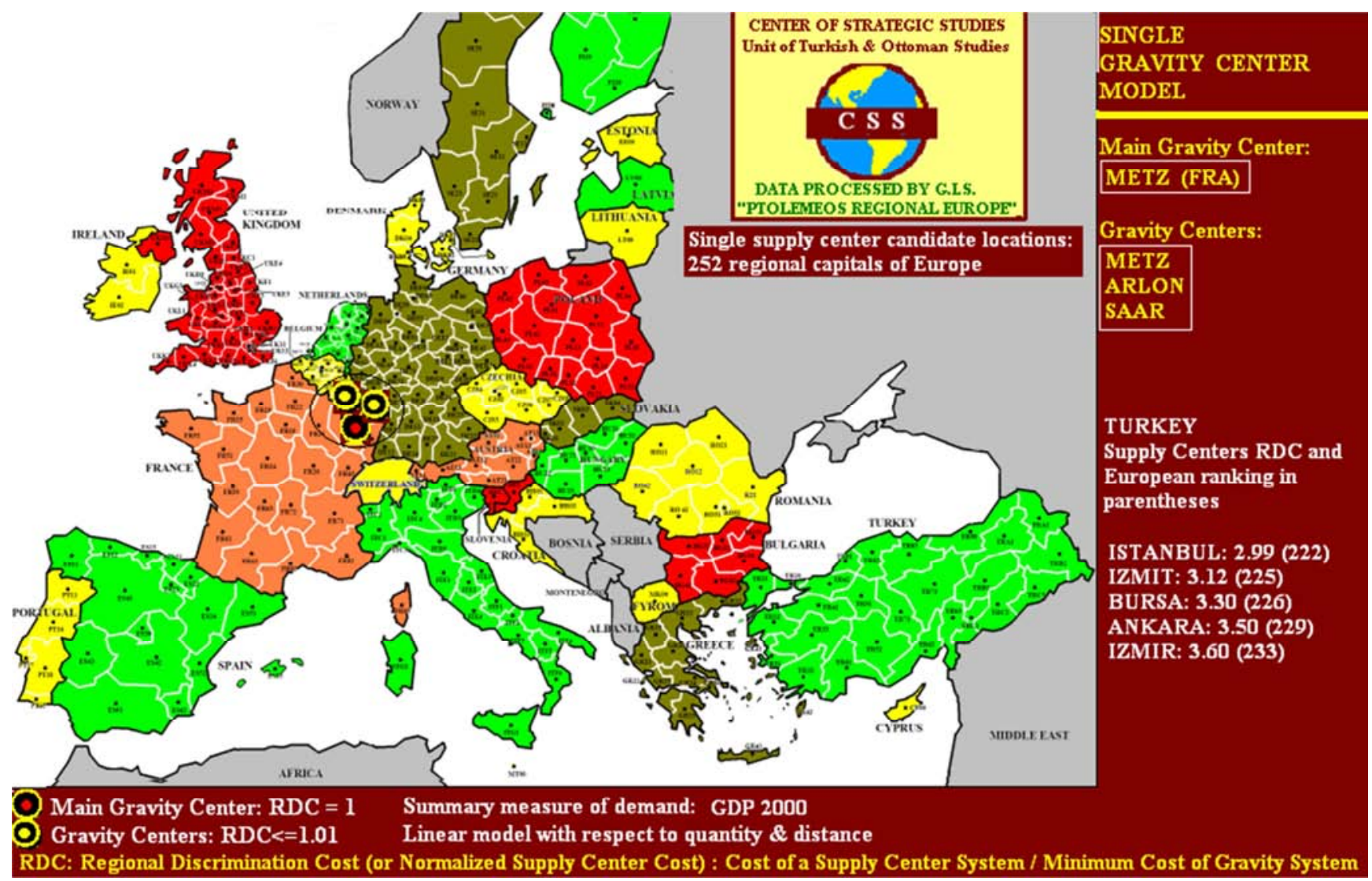

Figure 7. Single Gravity Centers of Europe. GDP 2000. Linear case. 


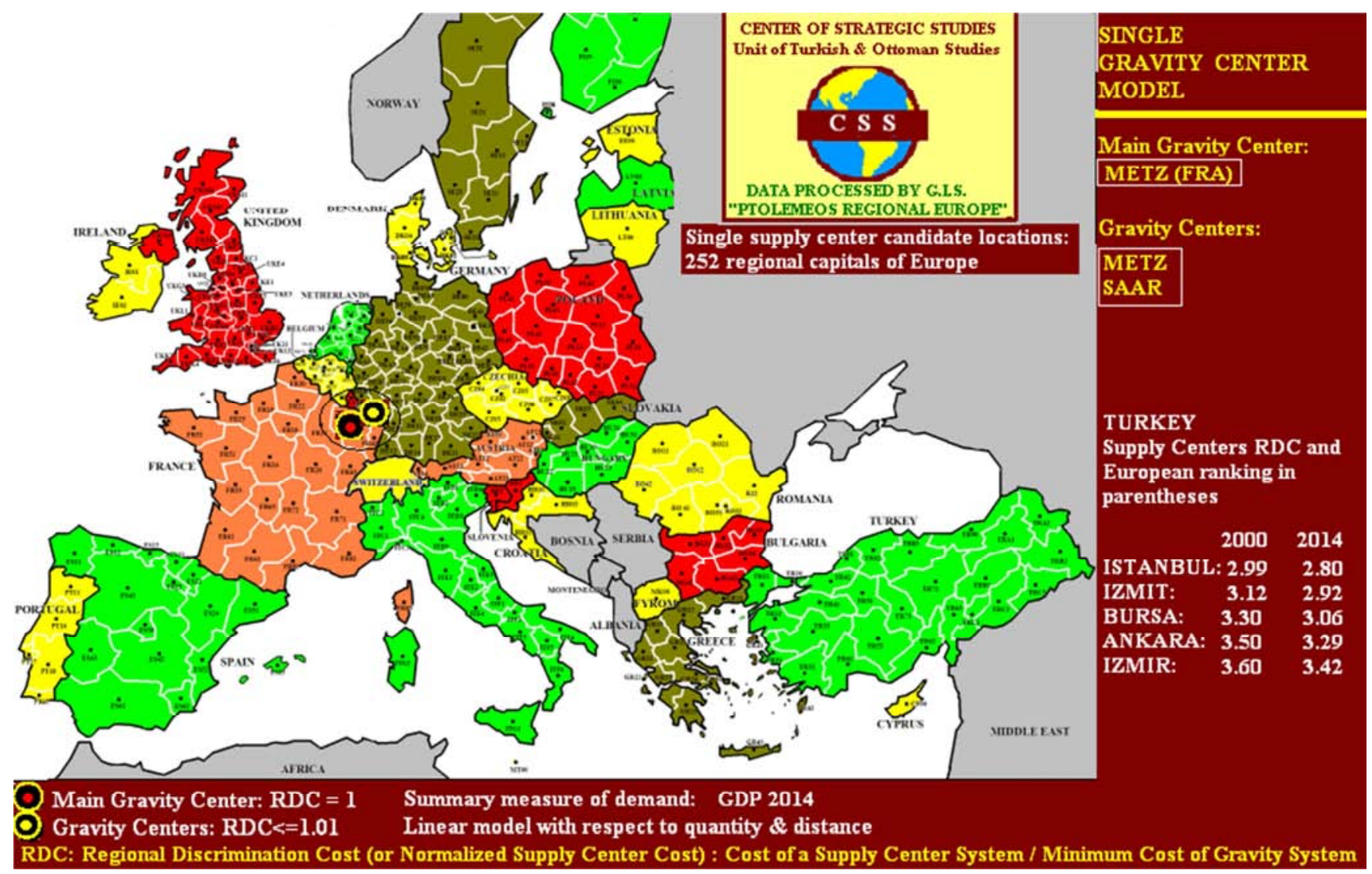

Figure 8. Single Gravity Centers of Europe. GDP 2014. Linear case.

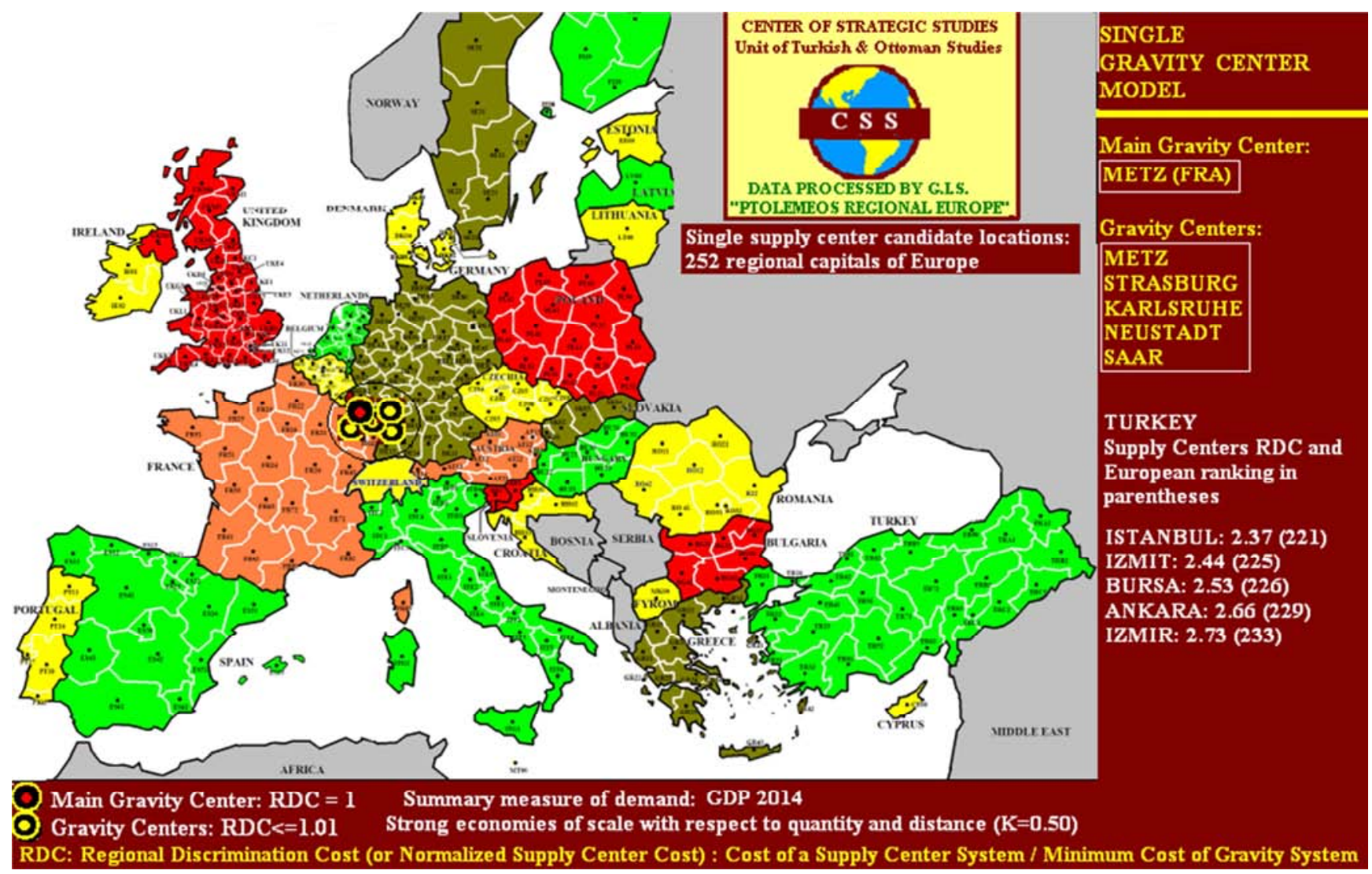

Figure 9. Single Gravity Centers of Europe. GDP 2014. Strong scale economies. 


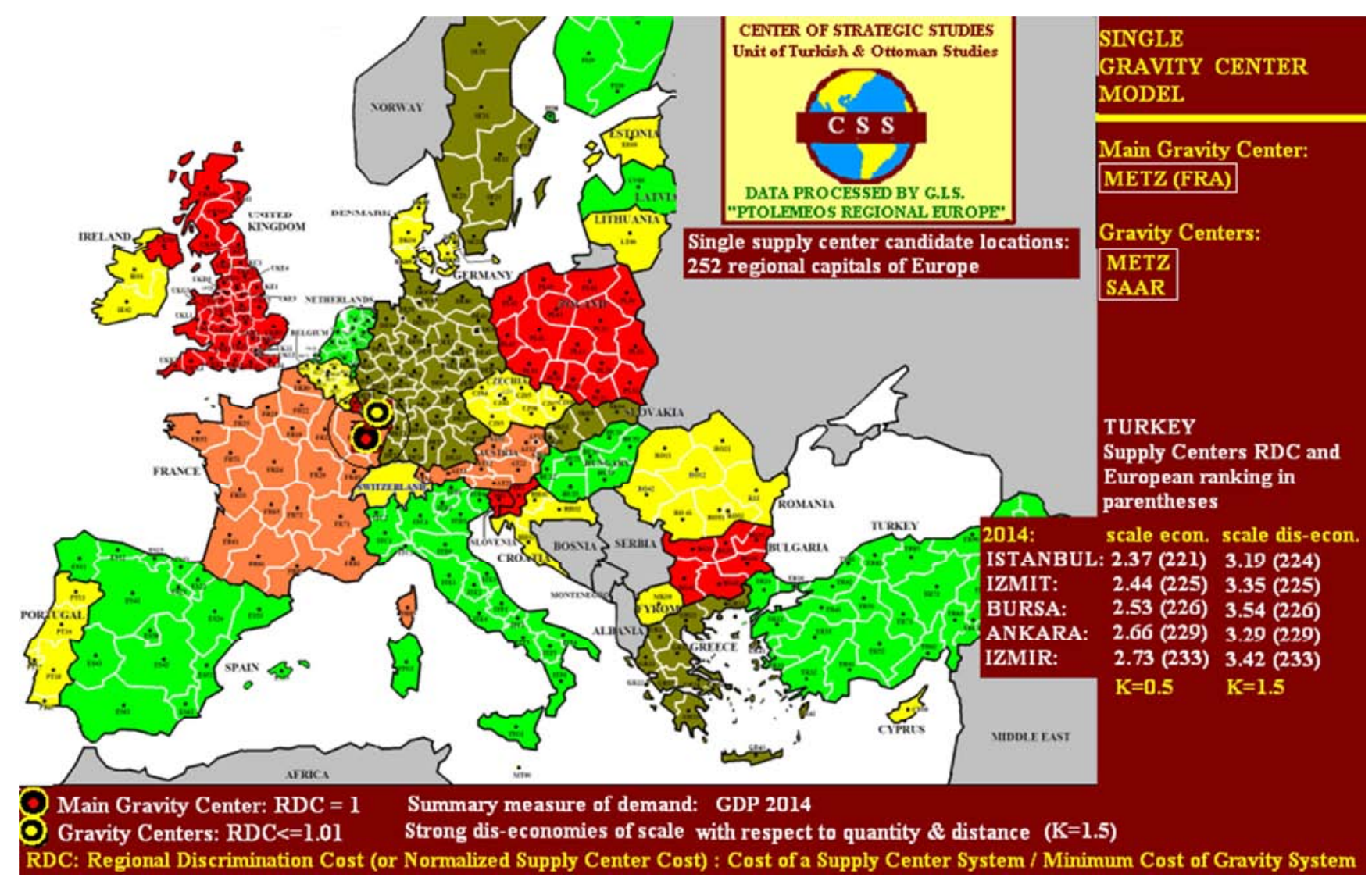

Figure 10. Single Gravity Centers of Europe. Population 2014. Strong scale dis-economies.

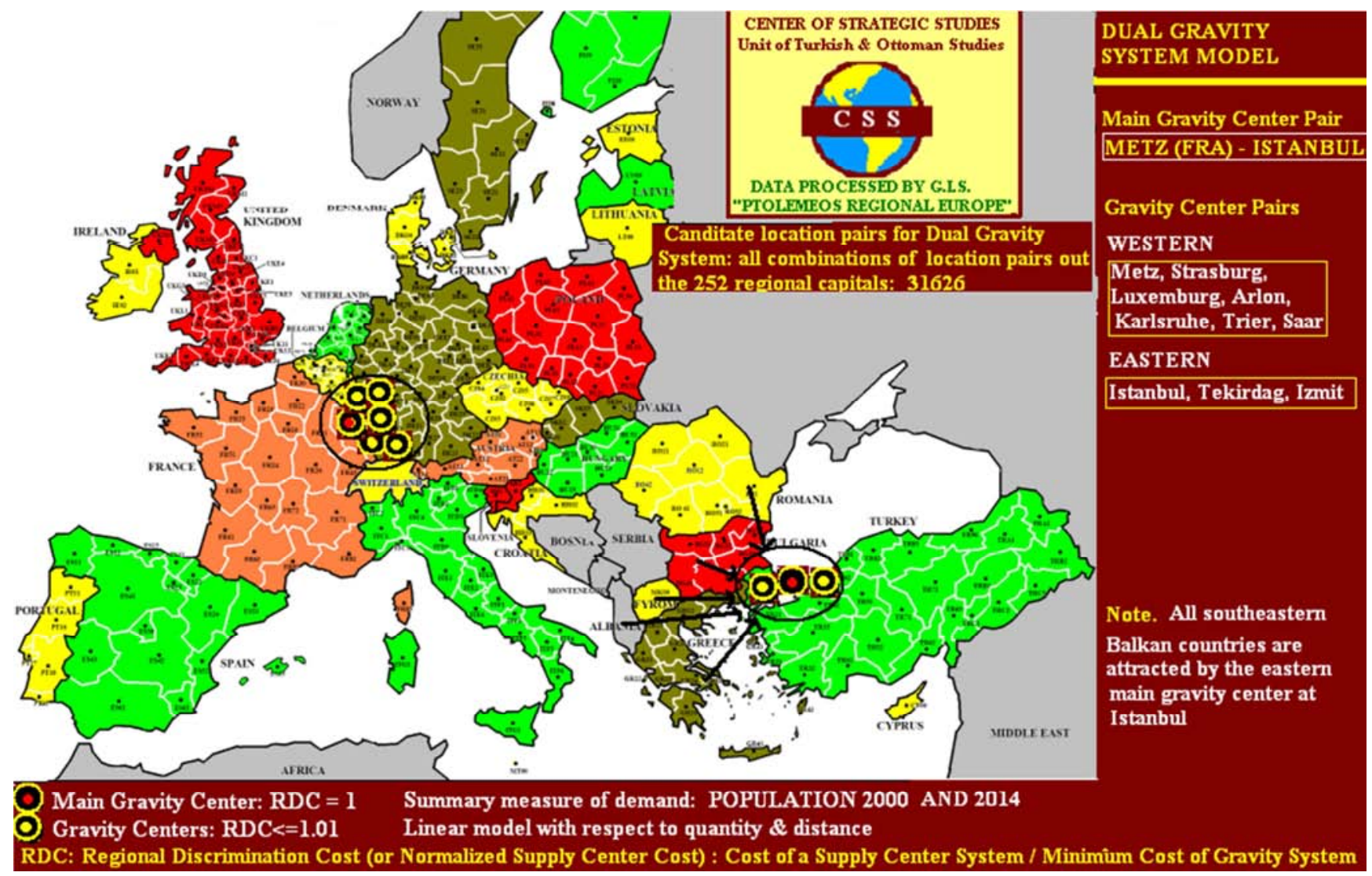

Figure 11. Dual Gravity Systems of Europe. Population 2000 \& 2014. Linear case. 


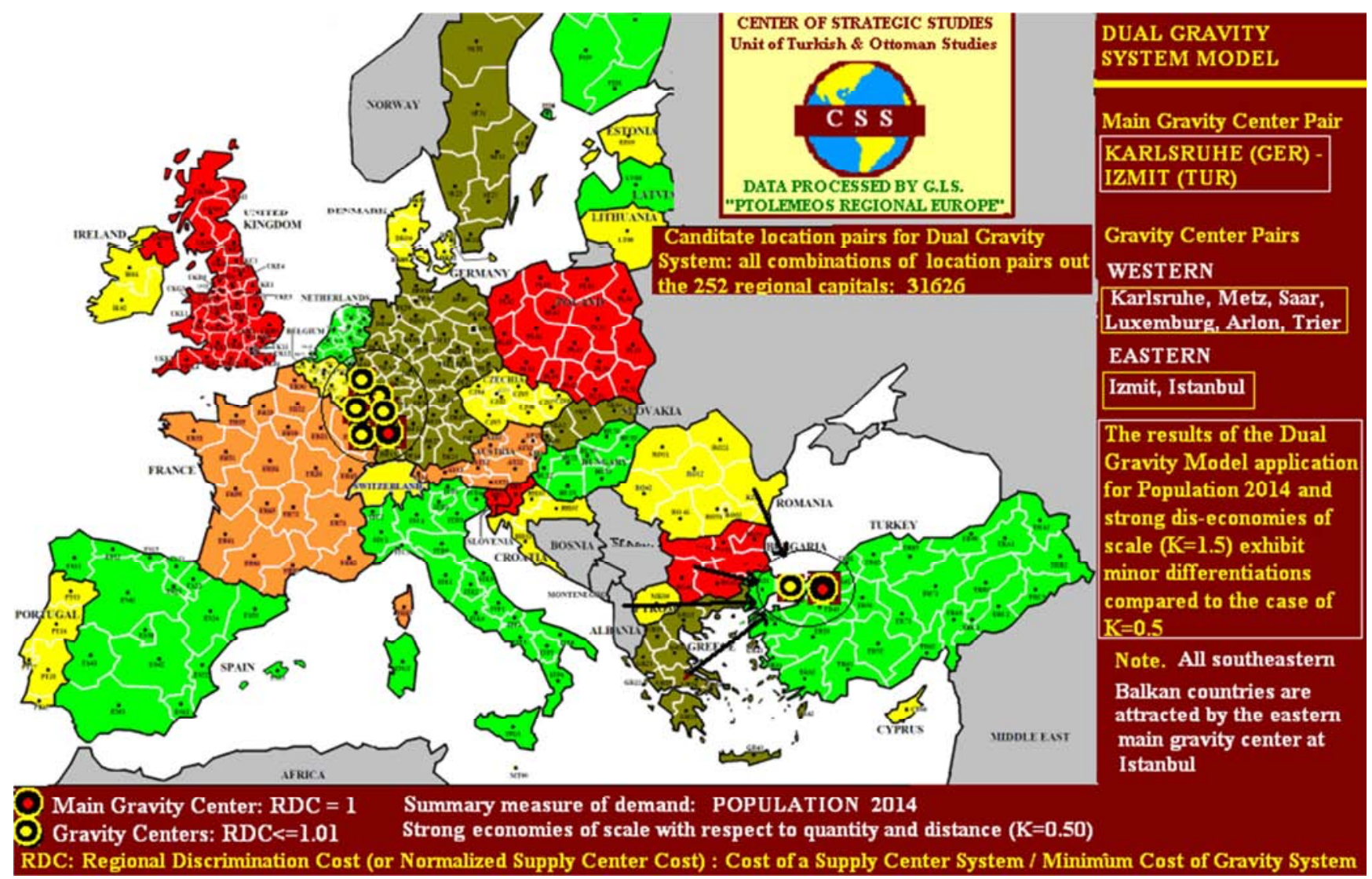

Figure 12. Dual Gravity Systems of Europe. Population 2014. Strong scale economies.

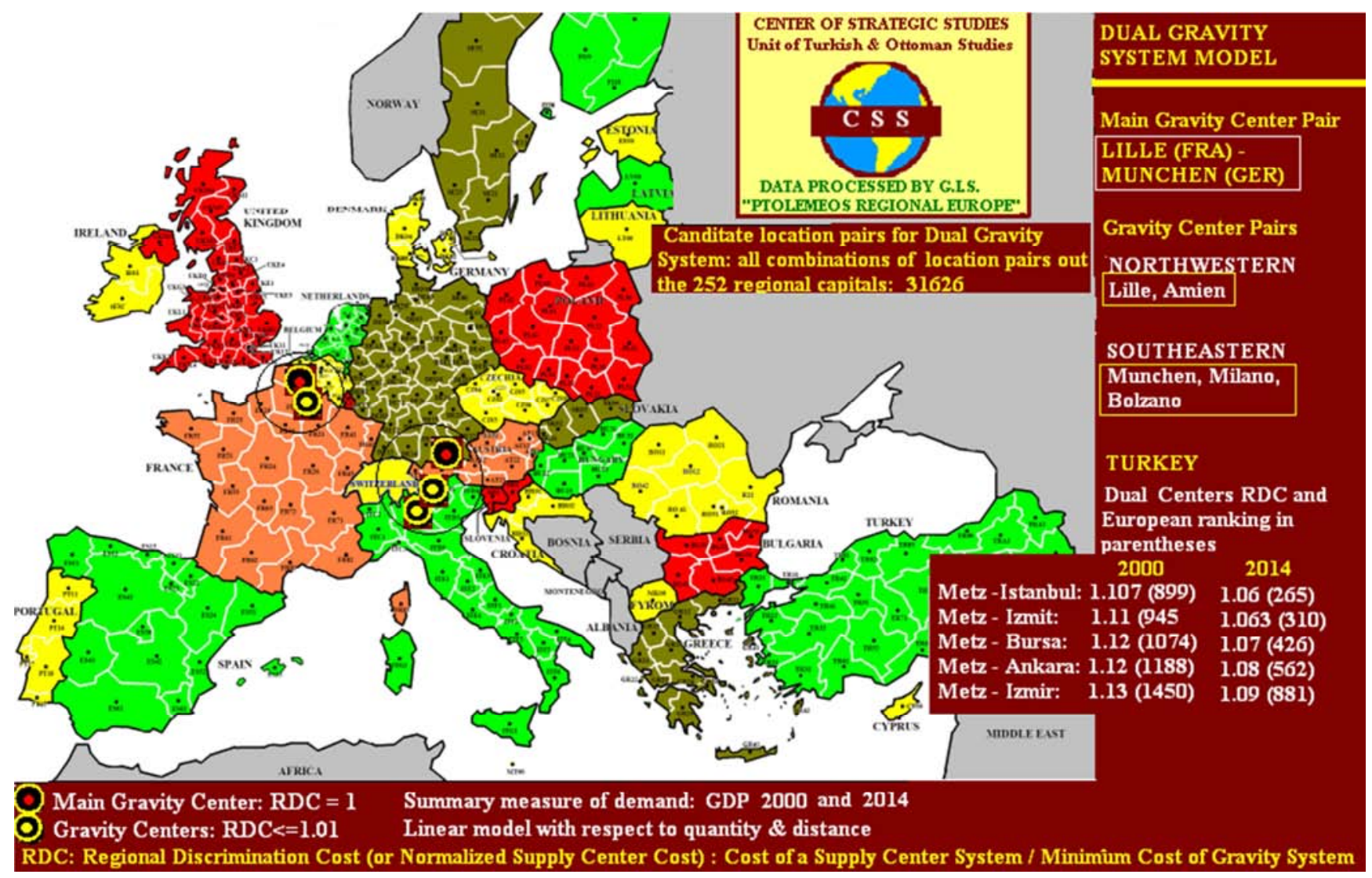

Figure 13. Dual Gravity Systems of Europe. GDP 2000 \& 2014. Linear case. 


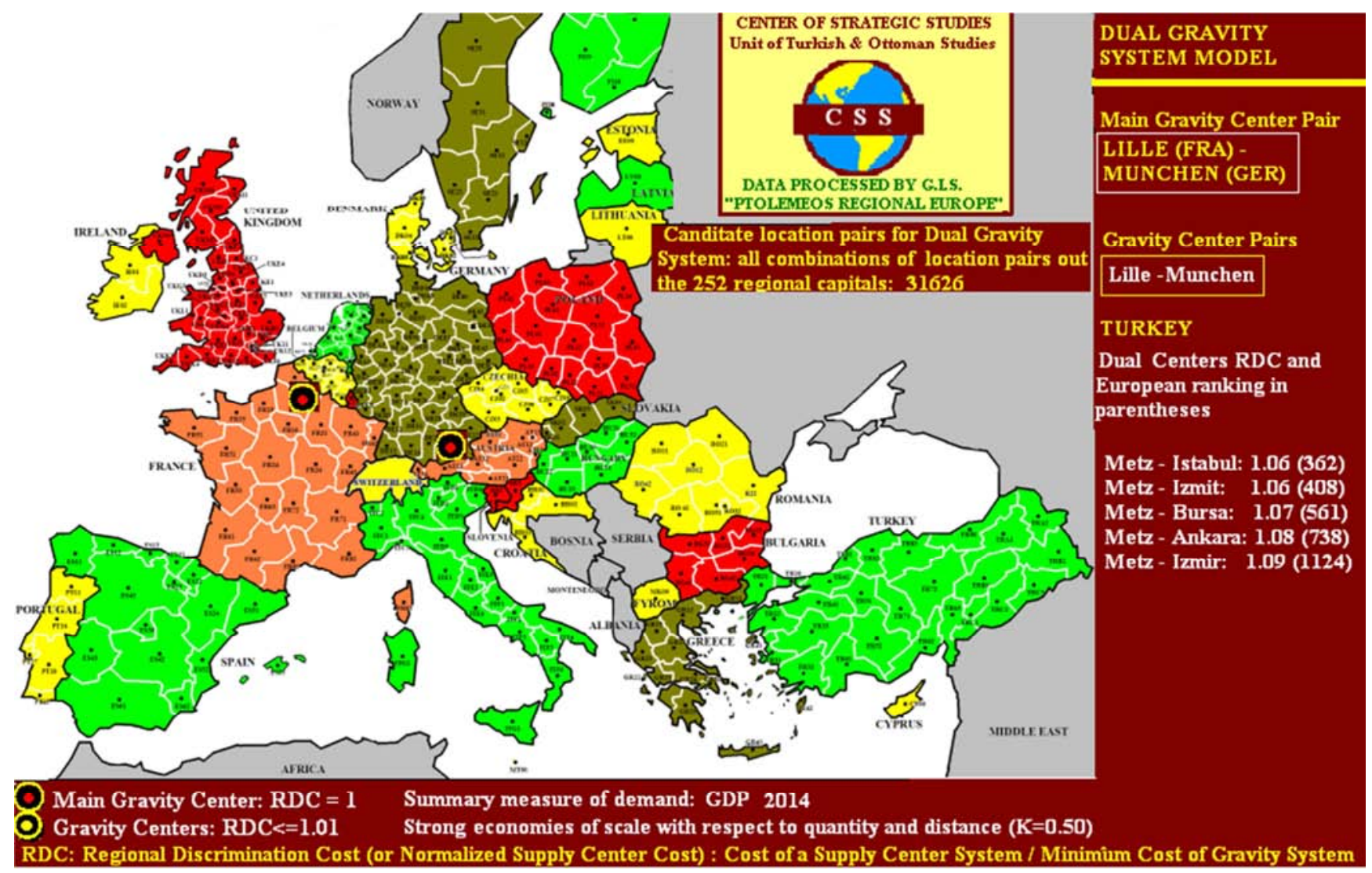

Figure 14. Dual Gravity Systems of Europe. GDP 2014. Strong scale economies.

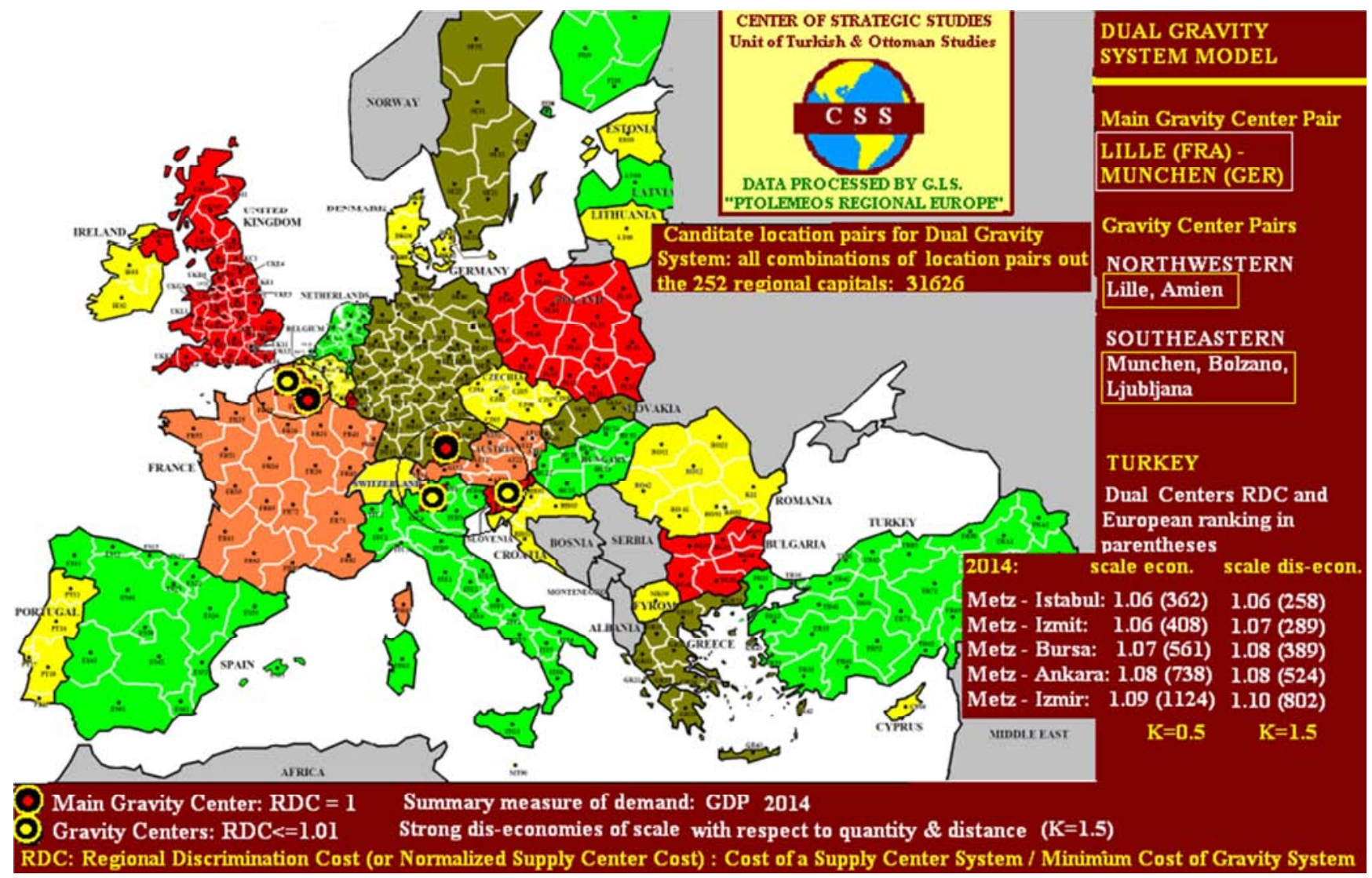

Figure 15. Dual Gravity Systems of Europe. GDP 2014. Strong scale dis-economies. 


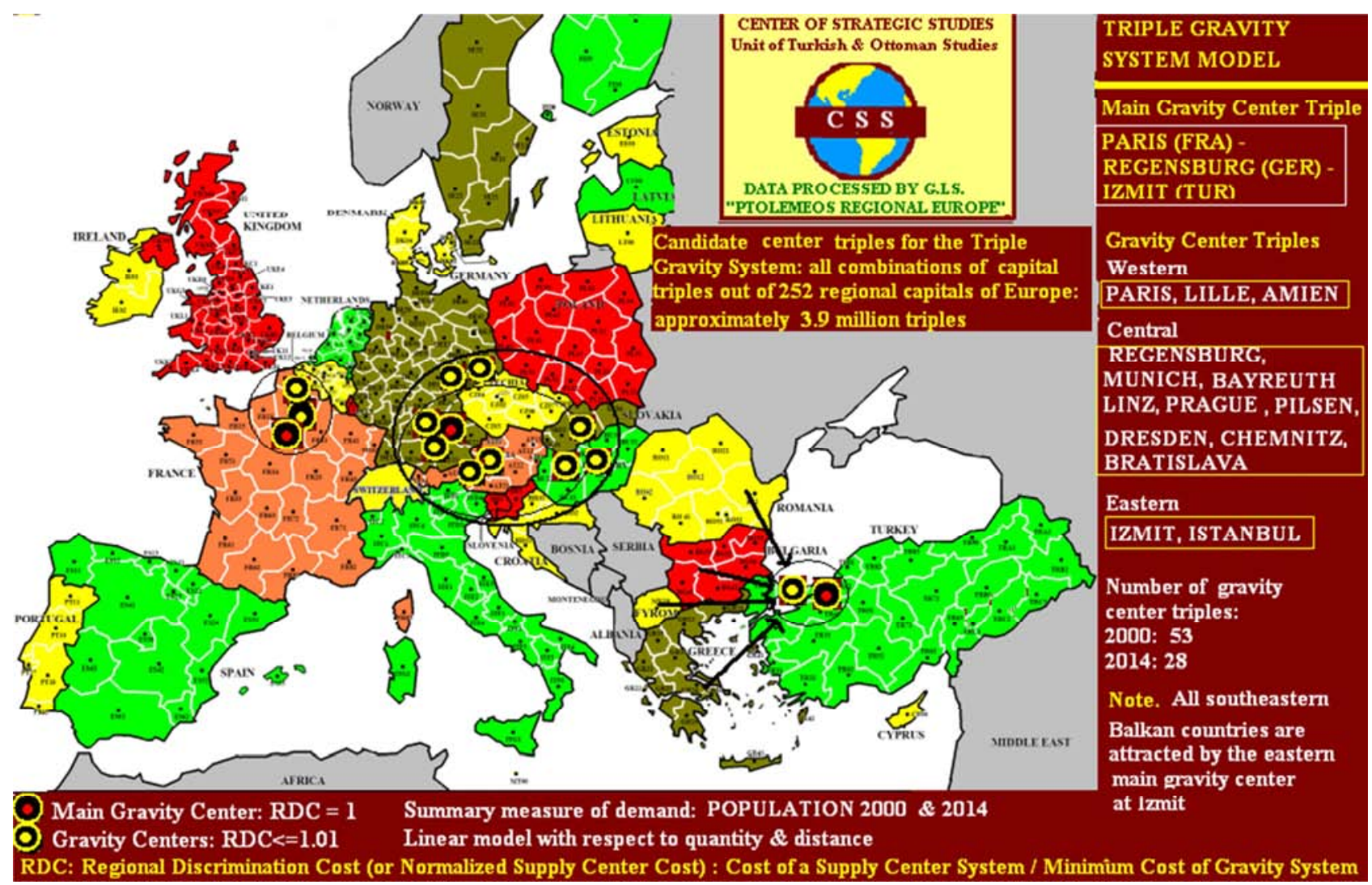

Figure 16. Triple Gravity Systems of Europe. Population 2000 \& 2014. Linear case.

'O' $\mathrm{K}=0.5$ \& $\mathrm{K}=1.5$

'O'] $\mathrm{K}=1.5$
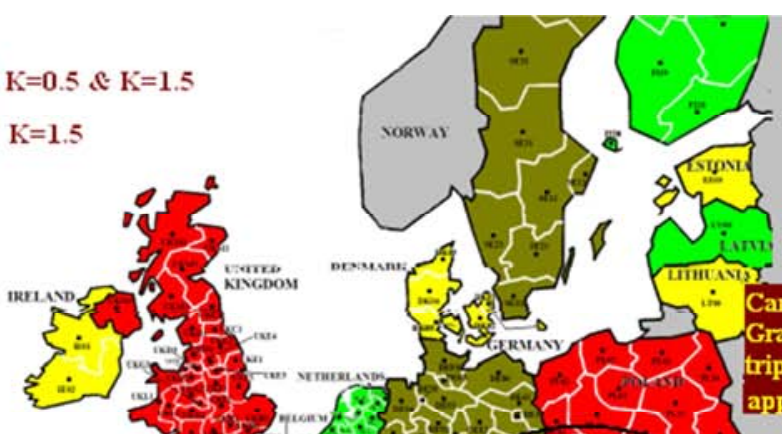

in

r.
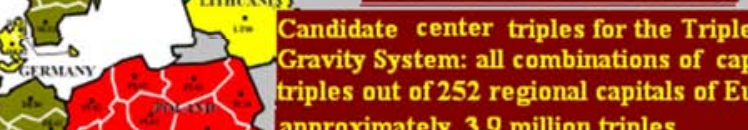

Gravity System: all combinations of capital

triples out of 252 regional capitals of Europe:

approximately 3.9 million triples
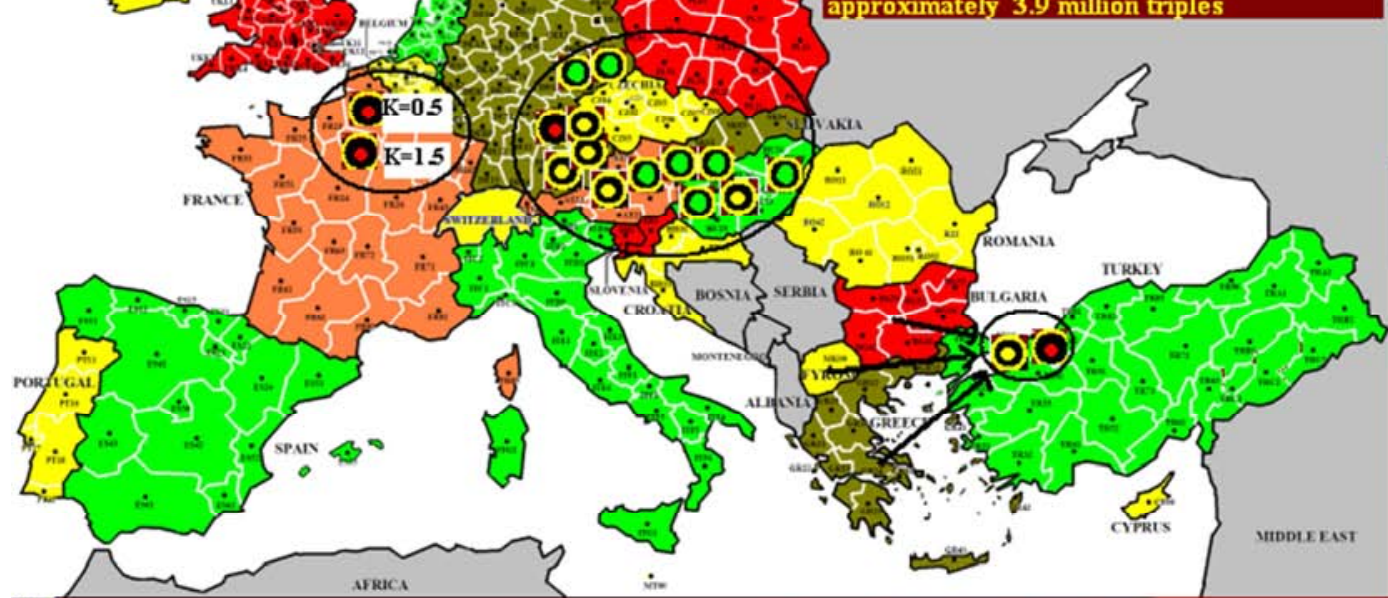

Main Gravity Center: RDC = 1

O Gravity Centers: $\mathrm{RDC}<=1.01$

Summary measure of demand: POPULATION 2014

Strong scale economies $(\mathrm{K}=0.5)$ and scale dis-economies $(\mathrm{K}=1.5)$ in quantity and distance

RDC: Regional Discrimination Cost (or Normalized Supply Center Cost) : Cost of a Supply Center System / Minimum Cost of Gravity System

Figure 17. Triple Gravity Systems of Europe. Population 2014. Strong scale economies \& dis-economies. 


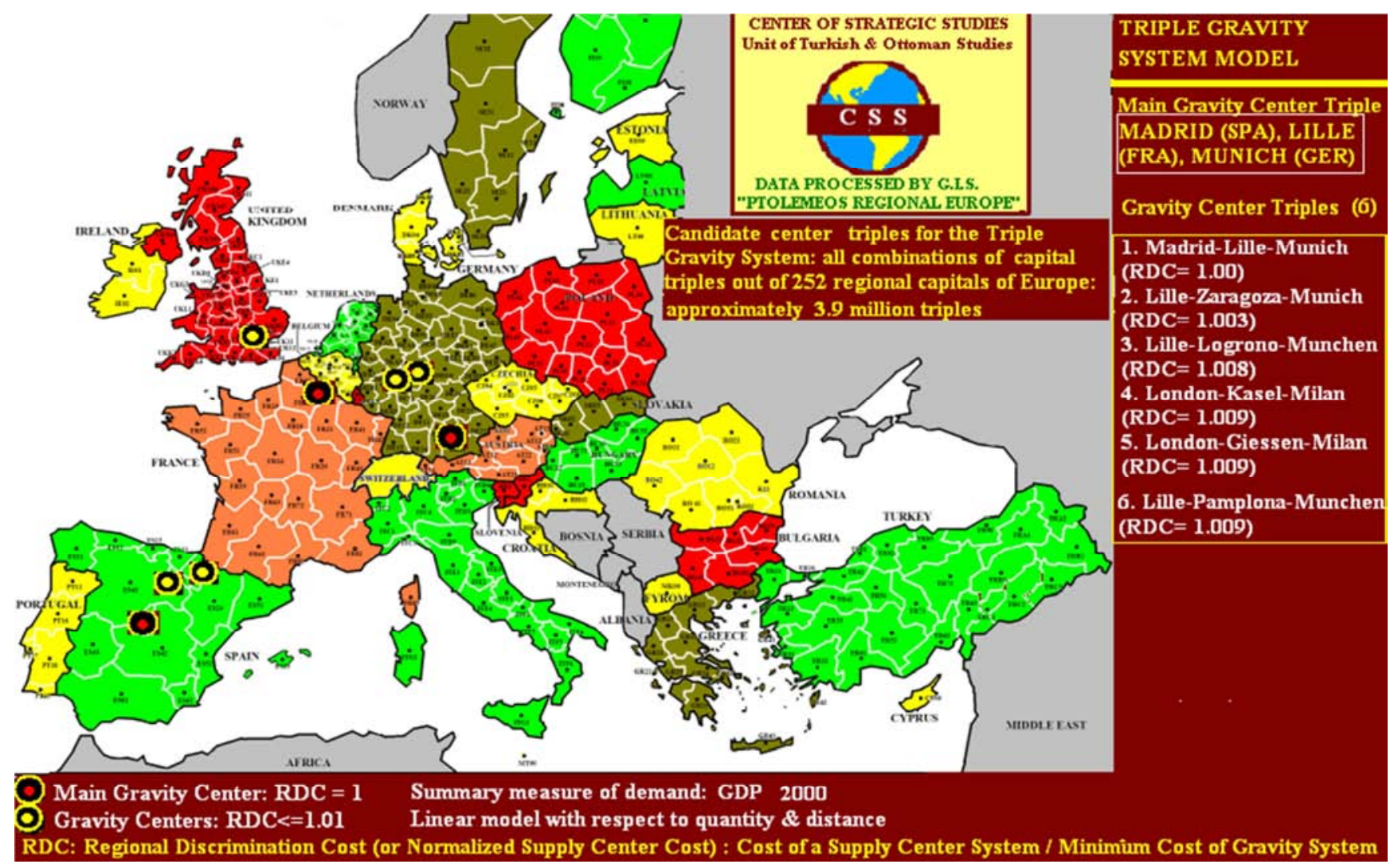

Figure 18. Triple Gravity Systems of Europe. GDP 2000. Linear case.

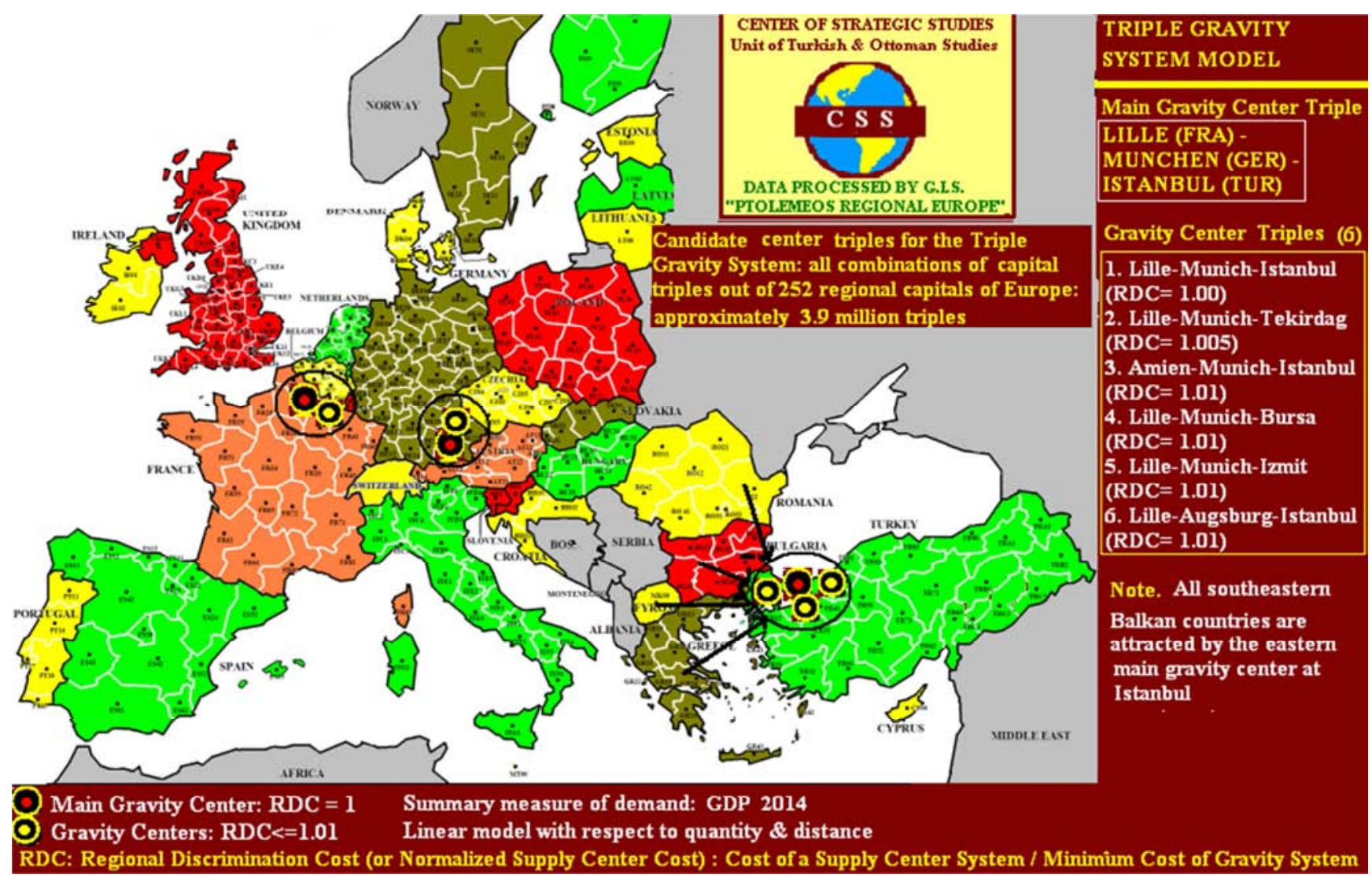

Figure 19. Triple Gravity Systems of Europe. GDP 2014. Linear case. 


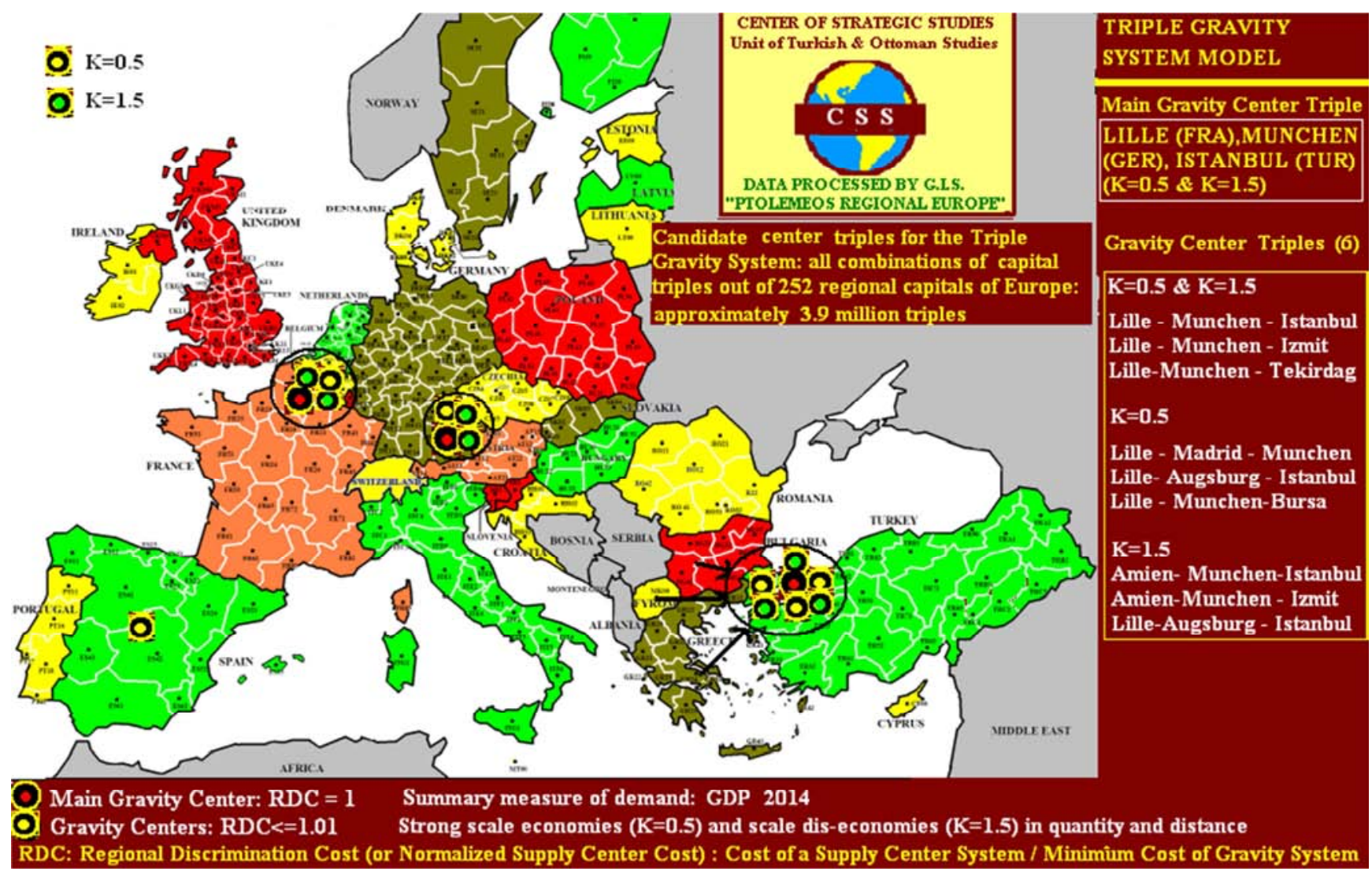

Figure 20. Triple Gravity Systems of Europe. GDP 2014. Strong scale economies and dis-economies.

\section{Conclusions}

Note that the term Europe encompasses, here, the 252 inland NUTS 2 regions of E.U., Turkey and FYROM.

\subsection{Single Gravity Centers of Europe}

As we will see in the following analysis southwestern Germany and eastern France accommodated all social and economic gravity centers of Europe for all types of scale economies. Furthermore one basic characteristic of the single location gravity system is its remarkable intra-time locational stability.

\subsubsection{Social Gravity Centers of Europe 2000-2014 (Demand Measure: Population)}

In 2000 the social gravity centers of Europe (linear transport costs) were all located in southern Germany. The western regions of Turkey were characterized by high RDC (Regional Discrimination Cost) variating in the interval 1.72 -2.19 , that is the total supply costs of those regions were $70 \%-120 \%$ higher than that of the regions of southern Germany. During the period 2000-2014 the above geoeconomic features exhibited limited differentiations (sections 5.1 and 5.2).

The introduction of strong economies of scale (section 5.3) in transport costs (with respect both to quantity and distance) for 2014 caused:

1. Limited relocations of the social gravity centers of
Europe (as compared to the linear case) and

2. A moderate decrease of the RDC of western regions of Turkey by $6 \%-13 \%$.

The introduction of strong dis-economies of scale (section 5.4) in transport costs (with respect both to quantity and distance) for 2014 caused:

1. Limited relocations of the social gravity centers of Europe (as compared to the linear case) and

2. A moderate increase of the RDC of western regions of Turkey by $6 \%-10 \%$.

\subsubsection{Economic Gravity Centers of Europe 2000-2014 (Demand Measure: GDP)}

In 2000 (section 5.5) the economic gravity centers of Europe (linear transport costs) were located around the Franco-German borders (Arlon, Metz, Saar). The western regions of Turkey were characterized by very high RDC variating in the interval $2.99-3.60$, that is the total supply costs of those regions were $200 \%-320 \%$ higher than that of the regions around the Franco-German borders. During the period 2000-2014 no significant alterations were recorded in the location of economic gravity centers. On the other hand, during the above period the RDCs of the western regions of Turkey decreased by $6 \%-8 \%$. (section 5.6 ).

The introduction of strong economies of scale (section 5.7) in transport costs (with respect both to quantity and distance) for 2014 caused:

1. Limited relocations of the economic gravity centers of Europe (as compared to the linear case) and 
2. A moderate to strong decrease of the RDC of western regions of Turkey by $13 \%-20 \%$.

The introduction of strong dis-economies of scale (section 5.8) in transport costs (with respect both to quantity and distance) for 2014 caused:

1. Limited relocations of the economic gravity centers of Europe (as compared to the linear case) and

2. A moderate increase of the RDC of western regions of Turkey by $0 \%-15 \%$.

\subsection{Dual Gravity Systems of Europe}

From the analysis that will follow (see sections 5.11, 5.12 and 5.13) one can conclude that northeastern France retained a geo-economic dominance over the period 200-2014 extending both to social and economic gravity centers and also to all types of scale economies examined. Actually, northern France accommodated throughout the above period the main western gravity center (Lille) of Europe for all scenarios examined. Regarding, now, the eastern pole of the dual system, western Turkey accommodated throughout 2000-2014 all social gravity centers of it (Istanbul, Izmit, Bursa etc) whereas southern Germany and northern Italy accommodated during the above period the majority of economic gravity centers of it (Munchen, Milan etc). Note, also, that the eastern main gravity center (Istanbul) attracted all southeastern Balkan regions. During this period the prevailing economic gravitational forces forced the eastern pole of the system to move considerably towards an eastern direction: Bolzano (Italy), which was an economic gravity center in 2000, gave its position to Ljubliana (Slovenia) in 2014.

One of the most interesting characteristics of the dual economic system of Europe is its intra-time locational instability.

Social Dual Gravity Systems of Europe 2000-2014 (demand measure: population)

In 2000 and for the linear case regarding transport cost the main gravity center $(\mathrm{RDC}=1)$ in western Europe is Metz (France) and in eastern Europe is Istanbul (Turkey). The western group of gravity centers $(\mathrm{RDC}<=1.01)$ consists of 3 German and 3 French regions and also Luxemburg. The eastern group of gravity centers consists of 3 Turkish regions: Istanbul, Tekirdag and Izmit. During the period 2000-2014 the above geo-economic pattern exhibited characteristic stability (section 5.9).

The introduction of strong economies of scale in transport cost causes no alterations in the above geoeconomic features with the only exemption being the substitution of Metz by Karlsruhe as the main gravity center of western Europe. The introduction of strong diseconomies of scale does not alter the above gravity centers pattern (section 5.10).

\subsection{Triple Gravity Systems of Europe}

During the period 2000-2014 the triple social gravity system of Europe exhibited remarkable stability (section
5.14). Throughout this period this system consisted of three distinct poles:

1. The western pole including 3 centers in northern France with the main one being Paris,

2. The central pole including 10 centers in central Europe ( 5 in southeastern Germany, 2 in Austria, 2 in Hungary and 1 in Slovakia) with its main one being at Regensburg. And

3 . The eastern pole including 2 centers in western Turkey with its main one being at Istanbul.

During the above period (section 5.15 and 5.16) the triple economic gravity system of Europe exhibited remarkable instability. Actually, in 2000 the triple economic gravity system of Europe consisted of the following three poles:

1. The southwestern pole including 3 centers in Spain with the main one located Madrid,

2. The northwestern pole including 2 centers in France and U.K. (Lille and London) with its main one located at Lille,

3 . The central pole including 3 centers in Germany with its main one located at Munich.

During the period 2000-2014 (section 5.16) significant alterations in the locational aspects of the triple economic system took place with the prevailing trend being relocations towards an eastern direction. Actually France retained its geo-economic significance with the Spanish gravity centers giving in 2014 their position to 4 centers in western Turkey (Istanbul, Tekirdag, Bursa and Izmir).

\section{References}

[1] Weber A. (1909), "Ueber den Standort der Industrien“, Tubingen, Germany (English translation: "Theory of the location of industries", C. J. Friedrich (translator), University of Chicago Press, Chicago, USA).

[2] Weiszfeld, E. (1936), "Sur le point pour lequel la somme des distances de $\mathrm{n}$ points donnes est minimum", Tohoku Mathematical Journal, Vol. 43, pp. 355-386.

[3] Boffey B. and J. Karkazis (1984), "p-Medians and multimedians", Journal of the Operational Research Society, Vol. 35, pp. 57-84.

[4] Athanassopoulos A. and J. Karkazis (1997), "The efficiency of social and economic image projection of spatial configurations", Journal of Regional Science, Vol. 37, 75-97.

[5] Karkazis J. and E. Thanassoulis (1998), “Assessing the effectiveness of regional development policies in Northern Greece using Data Envelopment Analysis", Socio-Economic Planning Sciences, Vol. 32, pp. 123-138.

[6] Karkazis J. (2000), "The social, economic and industrial gravity centers of the Balkans", Studies in Regional \& Urban Planning, Issue 7 Google Search: GEOPOL PROFILE, subpage: STUDIES IN REGIONAL AND URBAN PLANNING (Issues 1-9).

[7] "Transport Operational Program 2007", Turkish Ministry of Transport (CCI No: 2007 TR 16 I PO 002), Ankara, September 2007 https://ec.europa.eu/neighbourhoodenlargement/sites/near/file s/pdf/turkey/ipa/tk3_transport_op-final_2007_en.pdf 
[8] Karkazis J. (2007), "The impact of transport costs on the European geo-economic dynamics", Journal of Transport and Shipping, Issue 4, 2007.

[9] Dholakia N., Lennon M., Banerjee S., Paquin J. and A. Suerdem (2007), " Highway-based logistical links spanning Tokyo to Piraeus via Istanbul: Euro-Asian decentralized modular supply chains", Journal of Transport and Shipping, Issue 4, December 2007.

[10] Karkazis J. (2008), "Geographic Information System 'Ptolemeos - Regional Analysis - E. U. 15 and the Balkans'. User Manual and Applications", Strategic Reports (Center of Strategic Studies), Issue G8 Google Search: GEOPOL PROFILE, sub-page: GEOGRAPHIC INFORMATION SYSTEMS

[11] Turan I. (2011), "Turkey and the Mediterranean: Balancing Geopolitics and Geo-economics", The German Marshall Fund of the United States (GMF). Policy Brief, September 19, 2011 http://www.gmfus.org/publications/turkey-and-mediterraneanbalancing-geopolitics-and-geo-economics.

[12] Karkazis, J. (2011a), "Comparative Analysis of the Geoeconomic Profiles of German Regions in the Context of Europe", Studies in Regional \& Urban Planning, Issue 13.1 Google Search: GEOPOL PROFILE, sub-page: STUDIES IN REGIONAL AND URBAN PLANNING (Issues 10-15).

[13] Karkazis, J. (2011b), "Comparative Analysis of the Geoeconomic Profiles of Turkish Regions in the Context of Europe", Studies in Regional \& Urban Planning, Issue 13.1 Google Search: GEOPOL PROFILE, sub-page: STUDIES IN REGIONAL AND URBAN PLANNING (Issues 10-15).

[14] Karkazis J. (2012a), "Geographic Information System Regional Turkey", Studies in Regional and Urban Planning, Issue 15.1, 2012 http://www.stt.aegean.gr/geopolab/STUDIES\%20IN\%20REG IONAL\%20\&\%20URBAN\%20PLANNING\%202.htm

[15] Karkazis J. (2012b), "Geographic Information System
Regional Europe", Studies in Regional and Urban Planning, Issue $\quad 15.3, \quad 2012$ http://www.stt.aegean.gr/geopolab/STUDIES\%20IN\%20REG IONAL\%20\&\%20URBAN\%20PLANNING\%202.htm

[16] Karkazis J. (2012c), "Geographic Information System Transport Turkey", Studies in Regional and Urban Planning, Issue 15.4, 2012 http://www.stt.aegean.gr/geopolab/STUDIES\%20IN\%20REG IONAL\%20\&\%20URBAN\%20PLANNING\%202.htm

[17] "Investing in Transport Infrastructure of Turkey 2014", Turkish Ministry of Transport (Capt. Suat Hayri AKA, Deputy Undersecretary) http://www.confindustria.pu.it/allegati/notizie/n20140231_01. pdf

[18] Baltos G., Vidakis I. and J. Balodis (2017), "Turkey's Ambitions to Emerge as a Regional Power: Example or Counter-Example for Potential Aspiring Competitors", Academic Journal of Interdisciplinary Studies (sciendo), Vol. 6, November 2017.

[19] Karkazis J. and G. Baltos (2018a), "The Geo-economic Gravity Systems as a Tool for the Analysis of Socio-Economic Polarization in a Society: Country Case Study and Geographic Information Modelling Explain Long-term Transformation Potential towards Increased Regional Attractiveness and Efficiency", Academic Journal of Interdisciplinary Studies (sciendo), Vol. 7, July 2018.

[20] Karkazis J. and G. Baltos (2018b), "A Risk-based Assessment of Road Networks: Country Case-study and a Wide Range of Applications Covering from Logistics Operations and Security Controls to Regional Geo-economic Development", Academic Journal of Interdisciplinary Studies (sciendo), Vol. 9, November 2018.

[21] "Geographic Information System for Commission (GISCO, 2019)", EUROSTAT https://ec.europa.eu/eurostat/statisticsexplained/index.php/Geographical information system of th e_Commission_(GISCO) 